\title{
BMJ Open Socioeconomic status and self-reported health among middle-aged Japanese men: results from a nationwide longitudinal study
}

\author{
Koji Wada, ${ }^{1}$ Yoshiyuki Higuchi, ${ }^{2}$ Derek R Smith ${ }^{3}$
}

To cite: Wada K, Higuchi Y, Smith DR. Socioeconomic status and self-reported health among middle-aged Japanese men: results from a nationwide longitudinal study. BMJ Open 2015;5:e008178. doi:10.1136/bmjopen-2015008178

- Prepublication history for this paper is available online. To view these files please visit the journal online (http://dx.doi.org/10.1136/ bmjopen-2015-008178).

Received 13 March 2015 Revised 15 May 2015 Accepted 5 June 2015

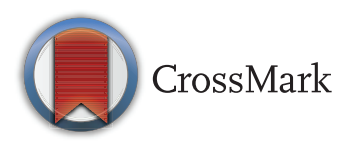

\footnotetext{
${ }^{1}$ International Health Cooperation, National Center for Global Health and Medicine, Tokyo, Japan ${ }^{2}$ Department of Health and Physical Education, Fukuoka University of Education, Fukuoka, Japan

${ }^{3}$ Faculty of Health and Medicine, School of Health Sciences, University of Newcastle, Ourimbah, New South Wales, Australia
}

Correspondence to Dr Koji Wada; kwada-sgy@umin.ac.jp

\section{ABSTRACT}

Objective: To examine potential associations between socioeconomic factors and self-rated health among a national sample of Japanese men aged 50-59 years between 2005 and 2010, including the 2008 global financial crisis.

Design: Prospective cohort study.

Setting: Randomly selected 2515 census areas from a total of 1.8 million census areas in Japan.

Participants: This study utilised data from a national, Iongitudinal survey conducted by the Ministry of Health, Labour and Welfare. Starting in 2005, 16738 Japanese men aged 50-59 years were recruited and sent a questionnaire each year. We analysed data for the 6-year period (2005-2010) from participants who had worked for over 20 years in the same industry $(\mathrm{n}=9727)$.

Main outcome measures: We focused on worsening self-rated health status by occupation, education and employment contract.

Results: Working in the manufacturing industry was associated with worsening self-rated health scores when compared to those working in management ( $\mathrm{HR}=1.19 ; 95 \% \mathrm{Cl} 1.04$ to 1.37). A relationship between education level and worsening self-rated health was also identified as follows: junior high school (HR=1.49; $95 \%$ Cl 1.31 to 1.69), high school (HR=1.29; $95 \% \mathrm{Cl} 1.17$ to 1.42), and vocational college ( $H R=1.25 ; 95 \% \mathrm{Cl} 1.07$ to $1.46)$, when compared with those holding universitylevel qualifications. Precarious employment $(\mathrm{HR}=1.17$; $95 \% \mathrm{Cl} 1.00$ to 1.37 ) was also associated with worsening self-rated health status in the current study.

Conclusions: This study suggests that working in manufacturing for more than 20 years and having lower education levels may have a significant impact on the self-rated health of middle-aged Japanese men. This may reflect a progressive decline in Japanese working conditions following the global financial crisis and/or the impact of lower socioeconomic status.

\section{INTRODUCTION}

From an occupational health perspective, economic recession is known to affect working conditions and employment security,

\section{Strengths and limitations of this study}

- This study describes one of the first longitudinal investigations conducted among a national sample of middle-aged men in a country where lifetime employment was previously the norm.

- A key strength was investigation of the interrelationships between self-rated health, economic circumstances and socioeconomic status.

- A possible limitation with this (and any longitudinal study) is that some participants were ultimately lost to follow-up, while others may have refused to participate due to negative health outcomes-the so-called 'healthy worker effect'.

- Further research is now needed to follow-up this cohort and establish whether the associations we found continued among the cohort after 2010.

which often lead to poorer health outcomes in the workplace. $^{1-3}$ The most recent example of this began in December 2007, when the USA faced a national economic emergency triggered by the subprime mortgage crisis, which ultimately resulted in the global financial crisis. ${ }^{4}$ This crisis, in turn, significantly impacted the Japanese economy, resulting in 'negative' national gross domestic product per capita for two consecutive years between 2008 and 2009-the first time this had happened since World War II. ${ }^{5}$ The Japanese economy's dependence on exports such as manufacturing led to reduced demand, while simultaneously the Yen's value rose to record highs against international currencies such as the US dollar (yearly average $=110.2$ yen in 2005, which increased to 87.8 yen in 2010). ${ }^{6}$ As a consequence, this resulted in a precarious financial situation for many Japanese companies that were dependent on exports. ${ }^{7}$

The impact of the economic recession often varies between times and countries. 
In the 1990s in Japan, for example, economic recession increased social stratification, even though the country was otherwise known as an egalitarian society. ${ }^{8}$ Kondo et $a t^{\theta}$ previously reported that self-rated health worsened among middle class, non-manual workers when compared with managers and administrators, a situation which resulted in widening health gaps during the economic recession of the 1990s. Conversely, a previous study of male Japanese workers reported that managers and professionals had increased age-adjusted mortality rates after the year 2000, when compared with those in manufacturing. ${ }^{1}$ Research conducted in Greece after 2008 found that healthy behaviours declined among the lower socioeconomic classes, which may eventually lead to a disproportionately higher risk of cardiovascular diseases in this group. ${ }^{10}$ In Ireland, the government was forced to scrutinise healthcare services more carefully because of austerity resulting in worsening health outcomes in the population. ${ }^{11}$

Since 2005, the Japanese Ministry of Health, Labour, and Welfare (MHLW) has been conducting a nationwide longitudinal survey of middle-aged and elderly persons, which targets people aged in their 50s and 60s. ${ }^{12}$ As such, these data represent an ideal opportunity to examine the impact of occupation and employment status on health. The MHLW data set monitored individuals' self-rated health, which is often referred to as a predictor of mortality and other health outcomes. ${ }^{13} 14$

Up until early 2008, Japanese men aged in their $50 \mathrm{~s}$ belonged to a unique generation which had generally enjoyed secure lifetime employment. ${ }^{15}$ They tended to work for the same company or industry for most of their adult working life, and had usually worked there for more than 20 years. Although most became used to the characteristics of their occupation over time, their duties and tasks in the workforce changed rapidly due to external influences following the 2008 economic recession. Despite this fact, the impact of socioeconomic factors such as occupation and education on worsening selfrated health among Japanese men is still not fully understood, especially among those who are middle-aged and have stayed with the same company over time. The contextual issue of age and employment among the Japanese has also been shown to be important in epidemiological research. ${ }^{16}$ Our study was undertaken, therefore, to examine these issues in detail and help redress the current knowledge gap.

\section{METHODS}

Participants and survey

This study utilised data from a nationwide longitudinal survey of middle aged and elderly people conducted by the Japanese MHLW. ${ }^{12}$ In October 2005, the Ministry randomly selected 2515 census areas from of a total of 5280 census areas which were also randomly selected for the Comprehensive Survey of Living Conditions and National Health and Nutrition Survey from 1.8 million census areas, classifying individuals aged $50-59$ years as being eligible (a total of 40877 men and women). A total of 34240 men and women responded to the first wave or baseline survey (response rate: $83.8 \%$ ). The MHLW subsequently mailed these people a questionnaire each year to monitor various health outcomes and working conditions. The response rate each year from 2005 to 2010 ranged from $91.8 \%$ to $97.3 \%$. Following approval by the Ministry, we extracted anonymous data for all 16738 males who had participated in the MHLW study between 2005 and 2010 .

Figure 1 depicts the flow chart used for exclusion during our analysis. First, we extracted data from all respondents who had worked for more than 20 years in the same company or industry $(\mathrm{n}=15150)$, which represented $90.5 \%$ of the total respondents and excluded 1588 including those who reported being unemployed. We then excluded individuals reporting any negative, self-rated health conditions during the baseline survey of 2005 ( $n=2928$ ). Finally, we extracted data from respondents who had completed all 6 years of the follow-up component, that being between 2005 and 2010 $(\mathrm{n}=9727)$.

\section{Measurement}

\section{Outcome (self-rated health)}

Each year, participants answered questions on self-rated health conditions such as "what is your current health status?' using a six-point Likert Scale (1, very good; 2, good; 3 , somewhat good; 4 , somewhat bad; 5 , bad; or 6 , very bad).

\section{Covariates}

We utilised baseline data for: occupation as contents of work (classified into 9 categories asking about their

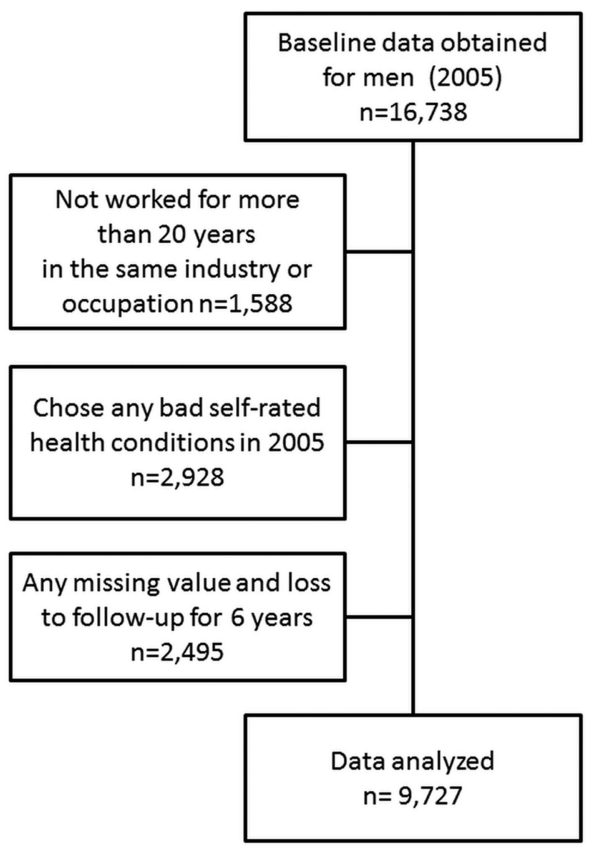

Figure 1 Flow diagram of the exclusion process. 
contents of work: management, professional, manufacturing, sales, service, clerk, transportation, agriculture and security), employment status (permanent, precarious (part-time or contract), or self-employed), completed education level (graduated from junior high school, high school, vocational school or university or postgraduate). Data was adjusted for age (as a continuous variable at baseline) and marital status (using the discrete variables of married, divorced/widowed or never married).

\section{Statistical analysis}

Statistical analyses were based on the incidence rates of worsening self-rated health during the 6-year follow-up period between 2005 and 2010. First, baseline characteristics were described by either means (including standard deviation (SD)) for age or percentages for other study variables and compared between occupations. Second, discrete-time survival analyses with Cox proportional hazard models were employed to determine the hazard ratio (HR) of occupation and other socioeconomic factors with worsening self-rated health. Participants were censored at the first worsening of selfrated health from any choices of good (1, very good; 2 , good or 3, somewhat good) to any choices of bad (4, somewhat bad; 5 , bad or 6 , very bad) or the end of the study period. In addition, Kaplan-Meier curves and log-rank tests were used to compare the cumulative incidence of worsening self-rated health in groups for two occupations and four different levels of education.

All analyses were conducted using SPSS (V.20.0; IBM SPSS, Armonk, New York) and R software.

\section{Ethics}

Ethical approval for this study was not required as the data were extracted from a national data set that had already been obtained by the MHLW and did not contain any personally identifiable information.

\section{RESULTS}

We analysed data from a total of 9727 men. Table 1 indicates the baseline association between occupation and the studied variables. Professionals $(28.3 \%)$ were the most common occupation in the studied population, followed by management (18.4\%). 'Permanent employment' status was dominant in this population $(72.3 \%)$. With regard to completed education levels, the most common category was high school graduate $(47.5 \%)$. With regard to marital status, the majority reported being married $(90.7 \%)$.

Cox proportional analyses revealed that occupations in manufacturing ( $\mathrm{HR}=1.19$; 95\% CI 1.04 to 1.37 ) had significant associations with worsening self-rated health when compared with management. In contrast, security workers ( $\mathrm{HR}=0.69 ; 95 \%$ CI 0.50 to 0.95$)$ were shown to have a lower risk of worsening self-rated health. The Kaplan-Meier survival estimates for worsening self-rated health in the manufacturing industry revealed a significant difference when compared with managers $(\mathrm{p}<0.01 ;$ log-rank test $)$. Precarious employment status ( $\mathrm{HR}=1.17$; 95\% CI 1.00 to 1.37 ) was associated with worsening self-rated health status in this study (table 2).

With regard to completed education levels, those with junior high school (HR=1.49; 95\% CI 1.31 to 1.69), high school (HR=1.29; 95\% CI 1.17 to 1.42$)$ and vocational college ( $\mathrm{HR}=1.25 ; 95 \%$ CI 1.07 to 1.46$)$ qualifications were at higher risk of worsening self-rated health when compared with university graduates or postgraduates. Kaplan-Meier survival estimates on worsening self-rated health by education level were statistically significant ( $\mathrm{p}<0.01$; log-rank test) in figure 2. For marital status, those who had never been married were at a higher risk of worsening general health conditions ( $\mathrm{HR}=1.20 ; 95 \%$ CI 1.02 to 1.41 ).

\section{DISCUSSION}

In this study, we examined the association of socioeconomic factors such as occupation, employment status and completed education levels on worsening self-rated health among Japanese men aged in their 50 s between the years 2005 and 2010, a period of time which included the 2008 global financial crisis following the US subprime mortgage crisis. Our investigation revealed that the self-rated health status of middle-aged male workers in the manufacturing industry with lower education levels was considerably affected. This finding may relate to economic difficulties in their industry during the follow-up period, specifically, ${ }^{9}$ or with lower socioeconomic status, more generally. ${ }^{17} 18$

On the basis of economic indicators alone, the Japanese manufacturing industry was significantly affected during the economic recession of 2008. For example, the total number of people working in manufacturing was 11.4 million in 2005, but this figure decreased to 10.5 million in 2010 (a $7.8 \%$ reduction), even though the number of non-manufacturing workers remained stable during this time, with around 52 million workers in the latter group. ${ }^{19}$ Additionally, precarious manufacturing work was legalised in 2004 to contribute to decreased employment costs for companies. Thus, the number of precarious workers in manufacturing increased up to 560000 in 2008, but this number fell suddenly to 250000 in 2009 , immediately following the economic recession, ${ }^{19}$ most likely because companies had terminated the contracts of precarious workers. Such sudden changes in employment status in manufacturing might conceivably worsen the health of workers, as demonstrated in this study. However, this result conflicts with a previous study showing that the mortality rate of Japanese men aged 30-59 years declined steadily at the same time as the mortality rate for managers increased. ${ }^{1}$ Additional studies will be needed to investigate the precise mechanisms of worsening self-rated health and mortality.

Although education is a well-known predictor of health outcomes, ${ }^{17} 18$ a literature review conducted by 
Table 1 Baseline associations between occupation and demographic variables among middle-aged Japanese men, 2005

\begin{tabular}{|c|c|c|c|c|c|c|c|c|c|c|c|c|}
\hline & \multicolumn{2}{|l|}{ All } & \multicolumn{2}{|c|}{ Management } & \multicolumn{2}{|c|}{ Professional } & \multicolumn{2}{|c|}{ Manufacturing } & \multicolumn{2}{|l|}{ Sales } & \multicolumn{2}{|c|}{ Service } \\
\hline & $\mathbf{N}$ & $(\%)$ & $\begin{array}{l}1789 \\
n\end{array}$ & $\begin{array}{l}(18.4) \\
(\%) \\
\end{array}$ & $\begin{array}{l}2757 \\
n\end{array}$ & $\begin{array}{l}(28.3) \\
(\%) \\
\end{array}$ & $\begin{array}{l}412 \\
n\end{array}$ & $\begin{array}{l}(14.5) \\
(\%)\end{array}$ & $\begin{array}{l}886 \\
n\end{array}$ & $\begin{array}{l}(9.1) \\
(\%) \\
\end{array}$ & $\begin{array}{l}790 \\
n \\
\end{array}$ & $\begin{array}{l}(8.1) \\
(\%)\end{array}$ \\
\hline \multicolumn{13}{|l|}{ Employment contract } \\
\hline Permanent & 7030 & (72.3) & 1654 & $(92.5)$ & 1807 & $(65.5)$ & 1091 & (77.3) & 536 & $(60.5)$ & 442 & $(55.9)$ \\
\hline Precarious & 533 & $(5.5)^{\prime}$ & 32 & $(1.8)$ & 104 & $(3.8)$ & 140 & $(9.9)$ & 34 & $(3.4)$ & 88 & (11.1) \\
\hline Self-employed & 2164 & $(22.2)$ & 103 & $(5.8)$ & 846 & $(30.7)$ & 181 & (12.8) & 316 & (1.3) & 260 & (32.9) \\
\hline \multicolumn{13}{|l|}{ Education completed } \\
\hline Junior high school & 1565 & $(16.1)$ & 74 & $(4.1)$ & 463 & (16.8) & 472 & (33.4) & 78 & $(8.8)$ & 124 & $(157)$ \\
\hline High school & 4621 & (47.5) & 738 & (41.3) & 1102 & (40.0) & 772 & (54.7) & 446 & $(50.3)$ & 428 & (54.2) \\
\hline Vocational school & 783 & $(8.0)$ & 116 & $(6.5)$ & 325 & (11.8) & 76 & $(5.4)$ & 51 & $(5.8)$ & 71 & $(9.0)$ \\
\hline University or postgraduate & 2758 & $(28.4)$ & 861 & $(48.1)$ & 867 & (31.4) & 92 & $(6.5)$ & 311 & $(35.1)$ & 167 & $(21.1)$ \\
\hline \multicolumn{13}{|l|}{ Marital status } \\
\hline Married & 8822 & $(90.7)$ & 1703 & (95.2) & 2514 & $(91.2)$ & 1211 & $(85.8)$ & 809 & $(91.3)$ & 713 & $(90.3)$ \\
\hline Divorced/widowed & 411 & $(4.2)$ & 48 & $(2.7)$ & 111 & $(4.0)$ & 74 & $(5.2)$ & 36 & $(4.1)$ & 36 & $(4.6)$ \\
\hline Never married & 494 & $(5.1)$ & 38 & $(2.1)$ & 132 & $(4.8)$ & 127 & $(9.0)$ & 41 & (4.6) & 41 & $(5.2)$ \\
\hline \multicolumn{13}{|l|}{ Age (years) } \\
\hline \multirow[t]{4}{*}{ Mean (SD) } & 54.8 & $(2.8)$ & 55.0 & $(2.7)$ & 54.5 & $(2.8)$ & 54.9 & $(2.7)$ & 54.9 & $(2.8)$ & 54.9 & $(2.8)$ \\
\hline & \multicolumn{3}{|c|}{ Clerk } & \multicolumn{3}{|c|}{ Transportation } & \multicolumn{3}{|c|}{ Agriculture } & \multicolumn{3}{|c|}{ Security } \\
\hline & \multirow{2}{*}{\multicolumn{2}{|c|}{$\begin{array}{l}787 \\
n\end{array}$}} & (8.1) & \multirow{2}{*}{\multicolumn{2}{|c|}{$\begin{array}{l}650 \\
\mathrm{n}\end{array}$}} & (6.7) & \multirow{2}{*}{\multicolumn{2}{|c|}{$\begin{array}{l}38 \\
n\end{array}$}} & (4.5) & \multirow{2}{*}{\multicolumn{2}{|c|}{$\begin{array}{l}218 \\
n\end{array}$}} & (2.2) \\
\hline & & & $(\%)$ & & & $(\%)$ & & & $(\%)$ & & & $(\%)$ \\
\hline \multicolumn{13}{|l|}{ Employment contract } \\
\hline Permanent & \multicolumn{2}{|c|}{750} & $(95.3)$ & \multicolumn{2}{|l|}{520} & $(80.0)$ & \multicolumn{2}{|l|}{55} & (12.6) & \multicolumn{2}{|c|}{175} & (80.3) \\
\hline Precarious & \multicolumn{2}{|c|}{27} & $(3.4)$ & 56 & & $(8.6)$ & 13 & & $(3.0)$ & & & $(17.9)$ \\
\hline Self-employed & & & (1.3) & 74 & & (11.4) & 370 & & (84.5) & & & $(1.8)$ \\
\hline Education completed & & & & & & & & & & & & \\
\hline Junior high school & & & $(1.9)$ & 195 & & $(30.0)$ & 118 & & $(26.9)$ & & & $(11.9)$ \\
\hline High school & 3 & & $(49.6)$ & 362 & & (55.7) & 252 & & (57.5) & & & $(60.1)$ \\
\hline Vocational school & & & $(6.4)$ & 46 & & $(7.1)^{\prime}$ & 34 & & $(7.8)^{\prime}$ & & & $(6.4)$ \\
\hline University or postgraduate & 3 & & (42.2) & 47 & & $(7.2)$ & 34 & & $(7.8)$ & & & $(21.6)$ \\
\hline Marital status & & & & & & & & & & & & \\
\hline Married & 7 & & $(92.9)$ & 561 & & (86.3) & 388 & & $(88.6)$ & & & $(88.1)$ \\
\hline Divorced/widowed & & & $(2.8)$ & 46 & & $(7.1)$ & 26 & & $(5.9)$ & & & $(5.5)$ \\
\hline Never married & & & (4.3) & 43 & & (6.6) & 24 & & $(5.5)$ & & & $(6.4)$ \\
\hline Age (years) & & & & & & & & & & & & \\
\hline Mean (SD) & & & $(2.7)$ & 54.9 & & $(2.8)$ & 54.9 & & $(2.8)$ & & & $(2.8)$ \\
\hline
\end{tabular}


Table 2 HRs for worsening self-rated health among middle-aged Japanese men, 2005-2010 ( $n=9727)$

\begin{tabular}{|c|c|c|c|c|c|}
\hline \multirow{2}{*}{$\overline{\text { Occupation }}$} & \multirow[t]{2}{*}{ Cases/Total } & \multicolumn{2}{|c|}{ Crude HR (95\% Cl) } & \multicolumn{2}{|c|}{ Adjusted HR (95\% Cl) } \\
\hline & & & & & \\
\hline Management & $440 / 1789$ & ref & & Ref & \\
\hline Professional & $730 / 2757$ & 0.99 & (0.96 to 1.22$)$ & 0.99 & (0.88 to 1.12 \\
\hline Manufacturing & $474 / 1412$ & 1.42 & (1.25 to 1.62$)$ & 1.19 & (1.04 to 1.37 \\
\hline Sales & $220 / 886$ & 1.01 & (0.86 to 1.18$)$ & 0.93 & ( 0.79 to 1.10 \\
\hline Service & $241 / 790$ & 1.28 & (1.09 to 1.49$)$ & 1.12 & (0.95 to 1.32 \\
\hline Clerk & $211 / 787$ & 1.10 & (0.94 to 1.30$)$ & 1.09 & (0.92 to 1.28 \\
\hline Transportation & $193 / 650$ & 1.23 & (1.04 to 1.46$)$ & 1.05 & (0.88 to 1.25 \\
\hline Agriculture & $128 / 438$ & 1.21 & (0.99 to 1.47$)$ & 0.98 & ( 0.79 to 1.22 \\
\hline Security & $43 / 218$ & 0.77 & (0.56 to 1.06$)$ & 0.69 & ( 0.50 to 0.95 \\
\hline \multicolumn{6}{|l|}{ Employment contract } \\
\hline Permanent & $1876 / 7030$ & Ref & & Ref & \\
\hline Precarious & $173 / 533$ & 1.25 & (1.07 to 1.46$)$ & 1.17 & (1.00 to 1.37 \\
\hline Self-employed & $631 / 2164$ & 1.11 & (1.01 to 1.21$)$ & 1.09 & (0.98 to 1.20 \\
\hline \multicolumn{6}{|l|}{ Completed education } \\
\hline Junior high school & $523 / 1565$ & 1.61 & (1.43 to 1.81$)$ & 1.49 & (1.31 to 1.69 \\
\hline High school & $1327 / 4621$ & 1.34 & (1.22 to 1.47$)$ & 1.29 & (1.17 to 1.42 \\
\hline Vocational school & $218 / 783$ & 1.29 & (1.11 to 1.51 ) & 1.25 & (1.07 to 1.46 \\
\hline University or postgraduate & $612 / 2758$ & Ref & & Ref & \\
\hline \multicolumn{6}{|l|}{ Marital status } \\
\hline Married & 2393/8822 & Ref & & Ref & \\
\hline Divorced/widowed & $123 / 411$ & 1.13 & (0.94 to 1.35$)$ & 1.07 & ( 0.89 to 1.28 \\
\hline Never married & $164 / 494$ & 1.29 & (1.10 to 1.51$)$ & 1.20 & (1.02 to 1.41 \\
\hline
\end{tabular}

Kagamimori $e t a l^{8}$ reported that the association between higher education and either mortality or morbidity was not strong. One cohort study in Japan that followed 40-59 year olds from 1990 to 2004 revealed that a lower grade of education incurred a higher mortality rate from all causes and cardiovascular diseases, but not for cancers. ${ }^{20}$ Another study indicated that lower education might be a predictor of premature death and smoking status, the latter being a habit which is clearly damaging to health. ${ }^{17} 18 \quad 21$ However, Tanno et $a l^{22}$ previously reported that self-rated health was not associated with education level among men.
Figure 2 Kaplan-Meier curves for worsening general health conditions among workers in management and manufacturing industries $(p<0.01$, log-rank test).

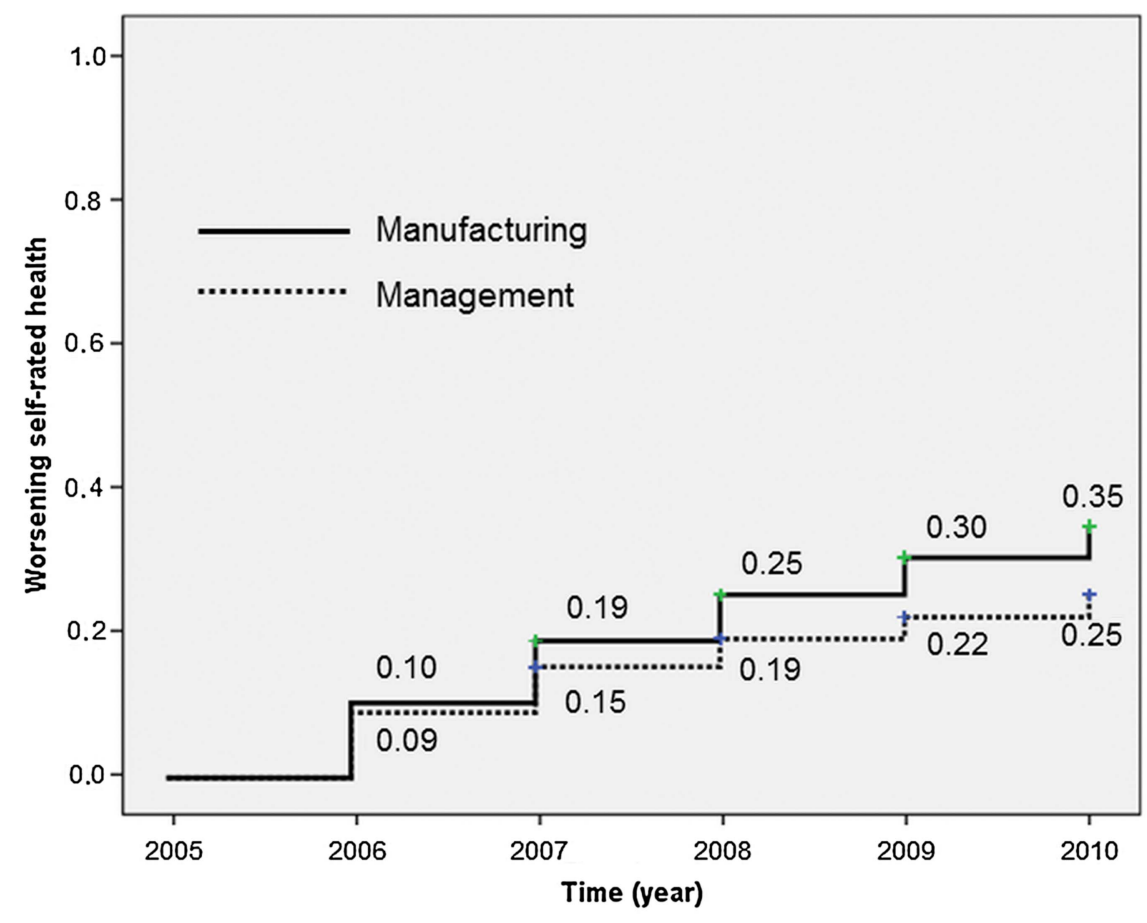


It is well known that, when compared with workers in more stable employment, precarious workers have a higher risk of negative health outcomes. ${ }^{23-25}$ In 2013, a revised Japanese law known as the Stabilization of Employment of Older Persons was enacted. It required companies to increase their retirement age up to 61 years and at the rate of 1 year of age every 3 years until 2025, to reach a retirement age of 65 years. ${ }^{26}$ However, companies receive an entitlement if they hire people older than 60 years as regular or precarious workers. Many companies will therefore hire workers in this age group on precarious terms to help defray employment costs. In this study, the proportion in precarious employment was relatively small (5.5\%); however, the number of precarious workers aged in their 60 s will most likely increase in the near future. As such, additional measures such as social protection policies are clearly needed at a national level to resolve these issues in Japanese society. educational strategies will also be important among this age group. ${ }^{16}$

Another interesting finding in this study was that security workers appeared to have a generally lower risk of worsening self-rated health status. This group included individuals who had worked for more than 20 years in such jobs as policemen, firefighters and officers of the Japanese self-defense forces. One possible reason for this result was that individuals working in physically demanding employment, such as the public security sector, are simply healthier than other workers more generally. To the best of our knowledge, there are few if any published studies of population-based epidemiological research that have described this issue in other countries.

This study may have incorporated a few limitations which are worth considering. First, a number of initial participants were lost to follow-up, while others may not have participated in the study simply because they experienced negative health outcomes-the so called 'healthy worker effect'. Even so, our investigation still represents one of the first longitudinal investigations conducted among a national sample of middle-aged men in a country where lifetime employment was previously the norm. Findings from our investigation clearly suggest that national interventions are needed to reduce the impact of precarious employment following economic recession in Japan. Second, there may have been more meticulous classifications that might have been used in each employment category, such as the company size the participants belong to and the working conditions of their companies. Owing to the retrospective nature of our study, this idea could not be incorporated into the original questionnaires. Further research should address these classifications in more detail. ${ }^{12}$ Third, even though the self-reported health status is a determinant of health, it incurs a certain potential limitation if, for example, participants develop a minor, transient illness (such as the common cold) at the time they are answering their survey. Similarly, participants who chose 'somewhat good' for self-rated health may be at higher risk of worsening their self-rated health, simply because they are staring at a relatively low level. As such, additional research will be needed in Japan as elsewhere to more carefully delineate the changes in self-reported health levels. Fourth, this longitudinal study in Japan continues to the present day, meaning that new data continue to be collected and the results updated. A final potential limitation was that the study focused exclusively on Japanese men (rather than women) simply because the proportion of Japanese women who have worked in the same industry for 20 years or more has been historically low in this country.

\section{CONCLUSIONS}

Overall, this study suggests that working in the manufacturing industry and having lower education levels has a significant impact on the self-rated health of middleaged Japanese men over time. This may reflect a progressive decline in Japanese working conditions following the global financial crisis and/or the impact of lower socioeconomic status.

Contributors KW and YH conceived and designed the experiments and analysed the data. KW and DRS wrote the manuscript.

Funding This work was supported by the Japan Society for the Promotion of Science, KAKENHI Grant-in-Aid for Scientific Research C, Grant Number 25460812. The funders had no role in the study design, the data collection or analysis, the decision to publish, or manuscript preparation.

\section{Competing interests None declared.}

Provenance and peer review Not commissioned; externally peer reviewed.

Data sharing statement The data analysed in this study can be obtained from the Ministry of Health, Labour and Welfare, Japan.

Open Access This is an Open Access article distributed in accordance with the Creative Commons Attribution Non Commercial (CC BY-NC 4.0) license, which permits others to distribute, remix, adapt, build upon this work noncommercially, and license their derivative works on different terms, provided the original work is properly cited and the use is non-commercial. See: http:// creativecommons.org/licenses/by-nc/4.0/

\section{REFERENCES}

1. Wada K, Kondo N, Gilmour S, et al. Trends in cause specific mortality across occupations in Japanese men of working age during period of economic stagnation, 1980-2005: retrospective cohort study. BMJ 2012;344:e1191.

2. Karanikolos M, Mladovsky $\mathrm{P}$, Cylus J, et al. Financial crisis, austerity, and health in Europe. Lancet 2013;381:1323-31.

3. Marmot M, Bell R. How will the financial crisis affect health? BMJ 2009;338:b1314.

4. Shiller R. The subprime solution: how today's global financial crisis happened, and what to do about it. Princeton University Press, 2008.

5. Bank TW. GDP growth (annual \%). Secondary GDP growth (annual \%) 2014. http://data.worldbank.org/indicator/NY.GDP.MKTP.KD.ZG?page=1

6. Nakajima T, Hamori S. Causality-in-mean and causality-in-variance among electricity prices, crude oil prices, and yen-US dollar exchange rates in Japan. Res Int Bus Finance 2012;26:371-86.

7. Tyers R. Japanese economic stagnation: causes and global implications*. Econ Rec 2012;88:517-36.

8. Kagamimori S, Gaina A, Nasermoaddeli A. Socioeconomic status and health in the Japanese population. Soc Sci Med 2009;68:2152-60.

9. Kondo N, Subramanian SV, Kawachi I, et al. Economic recession and health inequalities in Japan: analysis with a national sample, 1986-2001. J Epidemiol Community Health 2008;62:869-75. 
10. Filippidis FT, Schoretsaniti S, Dimitrakaki C, et al. Trends in cardiovascular risk factors in Greece before and during the financial crisis: the impact of social disparities. Eur J Public Health 2014;:24:973-8.

11. Thomas S, Burke S, Barry S. The Irish health-care system and austerity: sharing the pain. Lancet 2014;383:1545-6.

12. Ministry of Health Labour and Welfare. Longuitudinal survey of middle-aged and elderly persons. 2013. http://www.mhlw.go.jp/ english/database/db-ls/ls.html

13. Idler E, Benyamini Y. Self-rated health and mortality: a review of twenty-seven community studies. J Health Soc Behav 1997:38:21-37.

14. Pietilainen O, Laaksonen M, Rahkonen $\mathrm{O}$, et al. Self-rated health as a predictor of disability retirement-the contribution of ill-health and working conditions. PLOS ONE 2011;6:e25004.

15. Marmot M, Smith $\mathrm{G}$. Why are the Japanese living longer? BMJ 1989;299:1547.

16. Eguchi H, Wada K, Smith DR. Sociodemographic factors and prejudice toward HIV and hepatitis B/C status in a working-age population: results from a national, cross-sectional study in Japan. PLOS ONE 2014:9:e96645.

17. Honjo K, Iso H, Fukuda $\mathrm{Y}$, et al. Influence of municipal- and individual-level socioeconomic conditions on mortality in Japan. Int $J$ Behav Med 2014;21:737-49.

18. Fukuda $\mathrm{Y}$, Nakamura K, Takano T. Accumulation of health risk behaviours is associated with lower socioeconomic status and women's urban residence: a multilevel analysis in Japan. BMC Public Health 2005:5:53.

19. Ministry of Internal Affairs and Communications. Labour force survey. Secondary Labour Force Survey, 2014. http://www.stat.go.jp/ english/data/roudou/

20. Ito S, Takachi R, Inoue M, et al. Education in relation to incidence of and mortality from cancer and cardiovascular disease in Japan. Eur J Public Health 2008;18:466-72.

21. Oshio T, Kan M. Multidimensional poverty and health: evidence from a nationwide survey in Japan. Int J Equity Health 2014;13:128.

22. Tanno K, Ohsawa M, Onoda T, et al. Poor self-rated health is significantly associated with elevated C-reactive protein levels in women, but not in men, in the Japanese general population. J Psychosom Res 2012;73:225-31.

23. Kachi Y, Otsuka T, Kawada T. Precarious employment and the risk of serious psychological distress: a population-based cohort study in Japan. Scand J Work Environ Health 2014;40:465-72.

24. Tsurugano S, Inoue M, Yano E. Precarious employment and health: analysis of the Comprehensive National Survey in Japan. Ind Health 2012;50:223-35.

25. Nishikitani M, Tsurugano S, Inoue M, et al. Effect of unequal employment status on workers' health: results from a Japanese national survey. Soc Sci Med 2012;75:439-51.

26. Ministry of Health Labour and Welfare. Mandatory retirement system in Japan. Secondary Mandatory Retirement System in Japan, 2014. http://www.mhlw.go.jp/english/policy/affairs/dl/01.pdf 